\title{
DNA Stability in the Gas Versus Solution Phases: A Systematic Study of Thirty-One Duplexes with Varying Length, Sequence, and Charge Level
}

\author{
Su Pan, Xuejun Sun, and Jeehiun K. Lee \\ Department of Chemistry and Chemical Biology, Rutgers, The State University of New Jersey, Piscataway, \\ New Jersey, USA
}

We report herein a systematic mass spectrometric study of a series of thirty-one non-selfcomplementary, matched, DNA duplexes ranging in size from 5- to 12-mers. The purpose of this work is threefold: (1) to establish the viability of using mass spectrometry as a tool for examining solution phase stabilities of DNA duplexes; (2) to systematically assess gas-phase stabilities of DNA duplexes; and (3) to compare gas and solution phase stabilities in an effort to understand how media affects DNA stability. These fundamental issues are of importance both on their own, and also for harnessing the potential of mass spectrometry for biological applications. We have found that ion abundances do not always track with solution phase stability; GC content must be taken into account. Two duplexes with the same $T_{m}$ yet with differing GC content can yield different ion abundances. That is, if two duplexes have the exact same melting temperature, yet one has a higher GC content, the duplex with the higher GC content yields a higher ion abundance. It thus appears that not only is a GC base pair stronger than an AT base pair, but the relative strengths of each differ in the gas phase versus in solution, such that the electrospray process can differentiate between them. We also characterize the gas-phase stabilities of the duplexes, using collision-induced dissociation (CID) as a method to assess stability. We focus on two aspects of this CID experiment. One, we examine what factors appear to control whether the duplexes dissociate into single strands or covalently fragment; we are able to utilize a charge state normalization we coin "charge level" to compare our results with others' and establish generalities regarding dissociation versus fragmentation patterns. Two, we examine those duplexes that primarily dissociate and use CID to assess the gas-phase stabilities. We find that correlation of gas-phase to solution-phase stabilities is more likely to occur when duplexes of varying GC content are examined. Duplexes with the same GC content tend to have stabilities that do not parallel those in solution. We discuss these results in light of the different roles that hydrogen bonding and base stacking play in solution versus the gas phase. Ultimately, we apply what we learn to lend insight into the biological problem of how the carcinogenic, damaged nucleobase $\mathrm{O}^{6}$ methylguanine causes mutations. (J Am Soc Mass Spectrom 2006, 17, 1383-1395) (c) 2006 American Society for Mass Spectrometry

$\mathrm{T}$ The noncovalent association of DNA duplexes is one of the most important molecular recognition events in nature. Understanding the factors that lead to DNA duplex stability is of interest for fundamental reasons, as well as applied; DNA is the doorway through which the genome can be modified and manipulated $[1,2]$. In recent years, with the aid

\footnotetext{
Published online August 17, 2006

The authors dedicate this paper to Professor James McCloskey, and congratulate him on his receiving the 2005 Distinguished Contribution to Mass Spectrometry Award.

Address reprint requests to Dr. J. K. Lee, Department of Chemistry and Chemical Biology, Rutgers, The State University of New Jersey, Piscataway, NJ 08854, USA. E-mail: jklee@rutchem.rutgers.edu
}

of modern soft ionization methods, electrospray ionization (ESI) and matrix-assisted laser desorption/ ionization (MALDI), mass spectrometry (MS) has been extensively used in the characterization of noncovalent complexes [3-5]. The use of mass spectrometry for the study of large molecules has many advantages, such as sensitivity, speed, and the ability to assess stoichiometry $[4,6]$. Another motivation to examine biological molecules in the gas phase is that many biological media are nonpolar and the gas phase is the ultimate nonpolar environment from which intrinsic reactivity can be ascertained [7-9].

Our interest is in understanding the factors that contribute to duplex stability. In particular, we are 
intrigued by the question of how electrosprayed duplexes may or may not be similar to their aqueous and biological counterparts. As MS becomes a primary tool in biology, understanding what one sees in the gas phase becomes of paramount importance. The characterization of duplex stability in the gas phase can be accomplished by a variety of methods; one relatively straightforward technique is CID in an ion trap mass spectrometer [10-18]. In previous work, we focused on the behavior of a series of 9-mer complementary and mismatched DNA duplexes at the -4 charge state [19]. In the present work, we wish to further expand our understanding of gas-phase DNA behavior by examining a systematic series of duplexes that differ in sequence, length, and charge state. Our ultimate goal is to understand how DNA in the gas phase, which should reveal intrinsic behavior, is modified by media, whether that medium is aqueous solution, an enzyme active site, or cellular plasma.

The systematic study described herein is capped by a biomedical study. Guanine is alkylated by environmental mutagens to form $\mathrm{O}^{6}$-methylguanine (OMG) [20-23]. One of the mysteries of this transformation is that when replicating a DNA strand with OMG will pair that OMG with a thymine, rather than a cytosine (despite the fact that normal, undamaged guanine prefers cytosine) [24, 25]. Aqueous studies indicate that duplexes with OMG.C base pairs are more stable than those with OMG.T base pairs, so the preference of OMG for $\mathrm{T}$ in Nature is a mystery [26, 27]. The intrinsic, gas-phase affinity of OMG for $\mathrm{T}$ versus $\mathrm{C}$ is explored, capitalizing on what we learned in our systematic study. Because the polymerase enzyme that effects DNA replication may have a nonpolar active site, the preference of OMG for $T$ versus $C$ in the gas phase is relevant to biology. Using the techniques honed in this paper, we examine duplexes containing both OMG.C and OMG.T base pairs to ascertain whether in the absence of solvent OMG prefers $\mathrm{T}$ (in contrast to in aqueous solution).

\section{Experimental}

\section{Sample Preparation}

Desalted single stranded oligodeoxynucleotides were purchased from Sigma Genosys (The Woodlands, TX). To anneal the duplexes, stock solutions containing 62.5 $\mu \mathrm{M}$ each strand in $40 \mathrm{mM} \mathrm{NH}_{4} \mathrm{OAc}$ aqueous solution at $\mathrm{pH} 7.0$ were heated at $90{ }^{\circ} \mathrm{C}$ for $10 \mathrm{~min}$ then cooled down slowly to $0{ }^{\circ} \mathrm{C}$. The final ESI solution consisted of $12.5 \mu \mathrm{M}$ DNA duplex in $40 \mathrm{mM} \mathrm{NH} \mathrm{NH}_{4} \mathrm{OAc}$ mixed with $20 \%$ methanol.

\section{Melting Temperature in Solution}

The UV melting curves were obtained on an Aviv 14D-S spectrophotometer. All the measurements were performed at a duplex concentration of $5 \mu \mathrm{M}$ in $40 \mathrm{mM}$ $\mathrm{NH}_{4} \mathrm{OAc}$. Melts were monitored at $260 \mathrm{~nm}$ by increas- ing the temperature continuously from $0{ }^{\circ} \mathrm{C}$ to $80{ }^{\circ} \mathrm{C}$. Derivative curves were obtained using KaleidaGraph. The estimated precision for melting temperature experiments is $0.3^{\circ} \mathrm{C}$ [26].

We also estimated the $\mathrm{T}_{\mathrm{m}} \mathrm{s}$ for the DNA duplexes using the program MELTING [28]. The settings are as follows: (1) hybridization type: dnadna (for a DNA duplex); (2) nearest-neighbor parameters set: all97a.nn [29]; (3) salt concentration: $0.04 \mathrm{M}$; (4) nucleic acid concentration: $5 \mu \mathrm{M}$; (5) nucleic acid correction factor: 4 (for noncomplementary duplex [30]; (6) salt correction: san98a [31]. The error associated with the predicted $T_{m}$ using MELTING is $\pm 1.6{ }^{\circ} \mathrm{C}$ [31].

DNA duplexes with variable lengths (5 to 12 base pairs) were selected for stability studies. For each length, two duplexes with the same composition (and therefore the same molecular weight) but with different sequences were examined. The choice of sequences was guided by the MELTING program. For each length, we tried to choose isomeric duplexes that had different calculated melting temperatures. These choices, however, were also guided by the need to have low enough $\mathrm{T}_{\mathrm{m}} \mathrm{s}$ to ensure that CID would result in duplex dissociation into single strands, not covalent bond breakage (Table 1, vide infra) $[11,13-15,32]$. To simplify the nomenclature of each duplex in this paper, we use "I" to represent the more stable duplex in solution (higher $\mathrm{T}_{\mathrm{m}}$ ), and "II" for the less stable one in solution (lower $\mathrm{T}_{\mathrm{m}}$ ). For example, 5-mer-I is a duplex with 5 base pairs and it is more stable than 5-mer-II in solution.

\section{ESI-Quadrupole Ion Trap Mass Spectrometer}

Negative ion ESI-MS spectra were obtained with a Finnigan LCQ mass spectrometer (San Jose, CA). The $0{ }^{\circ} \mathrm{C}$ solution was infused at $25 \mu \mathrm{L} / \mathrm{min}$ directly into the mass spectrometer. The spray voltage was $-4.0 \mathrm{kV}$ while the capillary temperature was $175^{\circ} \mathrm{C}$. Duplex abundance is normalized by using the equation: \% Duplex $=(2 \times$ [all duplexes])/([all single strands] $+2 \times$ [all duplexes]), where the values in brackets are absolute ion abundances (measured using peak heights) [13]. The reported duplex percentage (DS\%) is an average of six full-scan measurements; the average standard deviation is $\pm 2.3 \%$ for the data in Table 1, and $\pm 0.88 \%$ for the 8-mers in Table 2 .

CID experiments were performed in an ion trap by varying the relative collision energy with a default activation time of $30 \mathrm{~ms}$ and a $q$ value of 0.25 . The isolation width for CID is $5 \mathrm{Da}$ for all duplex ions. For all the duplexes, the experimental parameters were kept constant. Experimental conditions were tuned by optimizing the -3 charged duplex ions of 8 -mer-II $(\mathrm{m} / \mathrm{z}=1605)$; the parameters thus obtained were applied to all the duplexes except those containing $\mathrm{O}^{6}$-methylguanine. The four 9-mer duplexes containing $\mathrm{O}^{6}$-methylguanine were examined under slightly different tuning conditions, which have been described previously [19].

The applied collision energy is a normalized collision energy (in \%) that corrects for the $\mathrm{m} / \mathrm{z}$ dependence of the 
Table 1. Sequence, molecular weight $\left(\mathrm{M}_{\mathrm{w}}\right)$, calculated melting temperatures $\left(\mathrm{T}_{\mathrm{m}, \mathrm{calc}}\right)$, experimental melting temperatures $\left(\mathrm{T}_{\mathrm{m}, \text { expt }}\right)$ and duplex abundance percentages (DS\%) for duplexes 5-mer-I to 12-mer-II

\begin{tabular}{|c|c|c|c|c|c|c|}
\hline Duplex Name & Sequence (ssX \& ssY) & $M_{w}(D a)$ & $\mathrm{T}_{\mathrm{m}, \text { calc }}\left({ }^{\circ} \mathrm{C}\right)$ & $\mathrm{T}_{\mathrm{m}, \operatorname{expt}}\left({ }^{\circ} \mathrm{C}\right)$ & DS\% & $E_{50}(\%)^{a}$ \\
\hline \multirow[t]{2}{*}{ 5-mer-I } & $5^{\prime}-\mathrm{GCGAT}^{\prime} 3^{\prime}$ & 1503.0 & -5.2 & 7.0 & 36.1 & $11.48 \pm 0.10[-3]$ \\
\hline & $3^{\prime}-$ CGCTA-5' & 1463.0 & & & & \\
\hline \multirow[t]{2}{*}{ 5-mer-II } & $5^{\prime}-\mathrm{CTGAG}-3^{\prime}$ & 1503.0 & -14.8 & 1.4 & 23.7 & $11.22 \pm 0.07[-3]$ \\
\hline & $3^{\prime}-\mathrm{GACTC}-5^{\prime}$ & 1463.0 & & & & \\
\hline \multirow[t]{2}{*}{ 6-mer-I } & 5'-GCGAAT-3' & 1816.3 & 5.9 & 14.0 & 49.9 & $12.57 \pm 0.10[-3]$ \\
\hline & $3^{\prime}-\mathrm{CGCTTA-5^{ \prime }}$ & 1767.2 & & & & \\
\hline \multirow[t]{2}{*}{ 6-mer-II } & $5^{\prime}-$ GTGTCA-3' & 1807.2 & 1.8 & 8.0 & 41.2 & $12.75 \pm 0.10[-3]$ \\
\hline & $3^{\prime}-\mathrm{CACAGT}-5^{\prime}$ & 1776.2 & & & & \\
\hline \multirow[t]{2}{*}{ 7-mer-I } & 5'-GCGCAAT-3' & 2105.4 & 22.1 & 24.8 & 56.9 & $\mathrm{n} / \mathrm{a}$ \\
\hline & 3'-CGCGTTA-5' & 2096.4 & & & & \\
\hline \multirow[t]{2}{*}{ 7-mer-II } & $5^{\prime}-T_{G A G A G C-3}$ & 2145.5 & 14.9 & 18.1 & 53.0 & $\mathrm{n} / \mathrm{a}$ \\
\hline & 3'-ACTCTCG-5' & 2056.4 & & & & \\
\hline \multirow[t]{2}{*}{ 8-mer-I } & 5'-GCGCGATT-3' & 2425.6 & 32.3 & 35.9 & 75.1 & $10.53 \pm 0.13[-4]$ \\
\hline & 3'-CGCGCTAA-3' & 2394.6 & & & & \\
\hline \multirow[t]{2}{*}{ 8-mer-II } & $5^{\prime}-$ TGACTGGC-3' $^{\prime}$ & 2425.6 & 26.9 & 29.1 & 57.9 & $10.27 \pm 0.08[-4]$ \\
\hline & 3'-ACTGACCG-5' & 2394.6 & & & & \\
\hline \multirow[t]{2}{*}{ 9-mer-I } & 5'-GGTTTTTGG-3' & 2775.9 & 24.8 & 27.7 & 58.2 & $10.61 \pm 0.03[-4]$ \\
\hline & $3^{\prime}-$ CCAAAAACC-5' & 2660.8 & & & & \\
\hline \multirow[t]{2}{*}{ 9-mer-II } & 5'-GGTTATTGG-3' & 2784.9 & 22.0 & 24.4 & 43.2 & $10.50 \pm 0.02[-4]$ \\
\hline & $3^{\prime}-$ CCAATAACC-5' & 2651.8 & & & & \\
\hline \multirow[t]{2}{*}{ 10-mer-I } & 5'-AAAAATTTCG-3' & 3035.1 & 23.5 & 28.6 & 30.6 & $\mathrm{n} / \mathrm{a}$ \\
\hline & 3'-TTTTTAAAGC-5' & 3017.0 & & & & \\
\hline \multirow[t]{2}{*}{ 10-mer-II } & 5'-TAGGTTATAA-3' & 3066.1 & 16.7 & 16.7 & 21.1 & $\mathrm{n} / \mathrm{a}$ \\
\hline & 3'-ATCCAATATT-5' & 2986.0 & & & & \\
\hline \multirow{2}{*}{ 11-mer-I } & 5'-AGAATTTATAA-3' & 3363.3 & 18.7 & 20.7 & 9.5 & $\mathrm{n} / \mathrm{a}$ \\
\hline & 3'-TCTTAAATATT-5' & 3305.2 & & & & \\
\hline \multirow[t]{2}{*}{ 11-mer-II } & 5'-TAGATTTATAA-3' & 3354.3 & 16.9 & 19.0 & 11.4 & $\mathrm{n} / \mathrm{a}$ \\
\hline & 3'-ATCTAAATATT-5' & 3314.3 & & & & \\
\hline \multirow[t]{2}{*}{ 12-mer-I } & 5'-AGAATTTATAAT-3' & 3667.5 & 22.0 & 24.6 & 6.9 & $\mathrm{n} / \mathrm{a}$ \\
\hline & 3'-TCTTAAATATTA-5' & 3618.5 & & & & \\
\hline \multirow[t]{2}{*}{ 12-mer-II } & 5'-TAGATTTATATT- $3^{\prime}$ & 3649.5 & 20.4 & 22.9 & 5.7 & $\mathrm{n} / \mathrm{a}$ \\
\hline & 3'-ATCTAAATATAA-5' & 3636.5 & & & & \\
\hline
\end{tabular}

a Value in brackets is the charge state that undergoes dissociation.

activation voltage required for ions of different $\mathrm{m} / \mathrm{z}$ ratios [33]. The gas-phase stability of the duplexes is measured in a relative way by subjecting the duplex parent ions to increasing collision energies during the CID event in an ion trap. $E_{50}$ is defined as the applied collision energy at which $50 \%$ of the duplexes are dissociated into single strands, and is used to characterize the gas-phase stability [11]. Duplex dissociation profiles were fitted with sigmoid equations, and the corresponding $\mathrm{E}_{50}$ values were derived using Origin 6.0 software [34]. The reported $\mathrm{E}_{50}$ value for each duplex is an average of three measurements. The average standard deviation of the $E_{50}$ values is \pm 0.06 . It should also be noted that while absolute $E_{50} \mathrm{~s}$, like $\mathrm{T}_{\mathrm{m}} \mathrm{s}$, can change under different experimental conditions, a series studied under the same conditions should have relatively comparable $\mathrm{E}_{50}$ values $[19,35]$.

\section{Results and Discussion}

Our goal is to systematically examine a series of duplexes that differ long and in sequence, and to examine how those differences are reflected in solution and gas-phase behavior, in an effort to make generalizations about gas-phase DNA structure and stability. Sixteen complementary duplexes with lengths varying from 5 to 12 base pairs were studied (Table 1). For a given length, the two duplexes have the same composition (and therefore the same molecular weight), but different sequences. The duplexes are named such that "I" represents the more stable duplex in solution (higher $\mathrm{T}_{\mathrm{m}}$, vide infra) and " $\mathrm{II}$ " represents the less stable duplex in solution (lower $\mathrm{T}_{\mathrm{m}}$ ). For example, 5-mer-I is a duplex with 5 base pairs and it is more stable than 5-mer-II in solution. The terms "ssX" and "ssY" refer to the two single strands that comprise each duplex; "ss $\mathrm{X}^{\text {" is }}$ always the strand with the higher mass in a given duplex. Therefore, for 5-mer-I, the single strand 5'GCGAT-3' (molecular weight $1503.0 \mathrm{Da}$ ) is ssX, while the complementary strand $3^{\prime}-$ CGCTA-5' (molecular weight $1463.0 \mathrm{Da}$ ) is ssY.

\section{Solution Phase Stability of DNA Duplexes (5-mer to 12-mer)}

Our first step is to assess the solution phase stability of the 16 duplexes, to provide a comparison point for the 
Table 2. GC\%, $\mathrm{T}_{\mathrm{m}, \text { calc }}, \mathrm{DS} \%$, and CID values for additional 8-mer duplexes

\begin{tabular}{|c|c|c|c|c|c|}
\hline Duplex Name & Sequence & $\mathrm{GC} \%$ & $\mathrm{~T}_{\mathrm{m}, \text { calc }}\left({ }^{\circ} \mathrm{C}\right)$ & DS\% & $E_{50}(\%)$ \\
\hline \multicolumn{6}{|l|}{ SERIES 1} \\
\hline 8-mer-A & $\begin{array}{l}\text { 5'-AAAAAAAA-3' } \\
3^{\prime} \text {-TTTTTTTI-5' }\end{array}$ & 0 & 4.7 & $25.6 \pm 0.6$ & $\mathrm{n} / \mathrm{a}$ \\
\hline 8-mer-B & $\begin{array}{l}5^{\prime} \text {-CAAAAAAG-3' } \\
3^{\prime} \text {-GTTTTTTC-5' }\end{array}$ & 25 & 11.1 & $25.7 \pm 1.4$ & $7.27 \pm 0.07$ \\
\hline 8-mer-C & 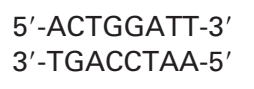 & 37.5 & 15.8 & $35.6 \pm 0.4$ & $9.02 \pm 0.06$ \\
\hline 8-mer-D & $\begin{array}{l}\text { 5'-AAGCGTAG-3' } \\
3^{\prime} \text {-TTCGCATC-5' }\end{array}$ & 50 & 21.9 & $51.9 \pm 1.5$ & $9.86 \pm 0.04$ \\
\hline 8-mer-E & $\begin{array}{l}5^{\prime}-\text { GAGGTCGT-3' } \\
3^{\prime} \text {-CTCCAGCA-5' }\end{array}$ & 62.5 & 25.9 & $70.5 \pm 0.4$ & $10.19 \pm 0.03$ \\
\hline 8-mer-F & $\begin{array}{l}\text { 5'-GAGCCGTG-3' } \\
3^{\prime}-\mathrm{CTCGGCAC-5}\end{array}$ & 75 & 31.3 & $81.6 \pm 0.2$ & $10.41 \pm 0.06$ \\
\hline \multicolumn{6}{|l|}{ SERIES 2} \\
\hline 8-mer-G & $\begin{array}{l}\text { 5'-AGAGAGAG-3' } \\
3^{\prime} \text {-TCTCTCTC-5' }\end{array}$ & 50 & 16.1 & $44.9 \pm 0.7$ & $9.73 \pm 0.01$ \\
\hline 8-mer-H & $\begin{array}{l}\text { 5'-GACTAGGT-3' } \\
3^{\prime}-\text { CTGATCCA-5' }\end{array}$ & 50 & 16.8 & $45.7 \pm 1.4$ & $9.14 \pm 0.08$ \\
\hline 8-mer-J & $\begin{array}{l}5^{\prime}-\mathrm{AGTCCAGA}-3^{\prime} \\
3^{\prime}-\mathrm{TCAGGTCT}-5^{\prime}\end{array}$ & 50 & 19.9 & $47.3 \pm 0.8$ & $10.03 \pm 0.07$ \\
\hline 8-mer-D & $\begin{array}{l}\text { 5'-AAGCGTAG-3' } \\
\text { 3'-TTCGCATC-5' }\end{array}$ & 50 & 21.9 & $51.9 \pm 1.5$ & $9.86 \pm 0.04$ \\
\hline 8-mer-K & $\begin{array}{l}\text { 5'-ATACAGCG-3' } \\
3^{\prime} \text {-TATGTCGC-5' }\end{array}$ & 50 & 22.1 & $55.1 \pm 1.7$ & $9.81 \pm 0.06$ \\
\hline 8-mer-L & $\begin{array}{l}5^{\prime}-\text { AAGCGCTA-3' } \\
3^{\prime}-3^{\prime} \text { TCGCGAT-5' }\end{array}$ & 50 & 25.4 & $61.1 \pm 0.2$ & $10.27 \pm 0.06$ \\
\hline
\end{tabular}

gas-phase stabilities. When the temperature of a DNA duplex is slowly increased, the ordered helical structure of the duplexes dissociates into two single strands. This dissociation is accompanied by an increase in UV absorption ("hyperchromicity") [36]. The midpoint of this transition is called the "melting temperature" $\left(\mathrm{T}_{\mathrm{m}}\right)$ and is used to characterize the stability of a DNA duplex in solution [1]. In solution, hydrogen bonding between base pairs is not the only factor that dictates DNA duplex stability; stacking is also important [29, 37, 38]. A base's immediate "neighbor" on a given strand will stack with that base, so the next neighbor plays a large role in affecting overall duplex stability. Therefore, two duplexes with the same composition (and therefore the same number of hydrogen bonds) but different sequences often have different $T_{m} s$. Studies have also established that solution phase $\mathrm{T}_{\mathrm{m}} \mathrm{s}$ are calculable for short DNA duplexes ( $<24$ base pairs), using empirical next-neighbor models [28, 29, 37, 38]. The accuracy of calculated $\mathrm{T}_{\mathrm{m}}$ values under ESI conditions (which differ from standard solution phase DNA melting conditions) has not heretofore been systematically tested [29, 37].

For each sequence, we first calculated the melting temperature $\left(\mathrm{T}_{\mathrm{m}, \text { calc }}\right)$, using the program MELTING [28]. We then measured the $T_{m}\left(T_{m, \text { expt }}\right)$ for each se- quence, to benchmark the calculated values (Table 1) [29]. To test the accuracy of the calculated values, we plotted $T_{m, \text { calc }}$ versus $T_{m \text {,expt }}$ (Figure 1). The data form two clear lines, of differing slope. For the 7- to 12-mers, the calculated $\mathrm{T}_{\mathrm{m} \text {,calc }}$ is slightly lower than the experimental $\mathrm{T}_{\text {m,expt }}$ values, but by a fairly constant amount, as indicated by the linearity of the relationship. For the 5- and 6-mers, the $T_{m, \text { calc }}$ is also lower than the $T_{m \text {,expt }}$ values by a fairly constant amount; this lowering is larger than for the 7- to 12-mers.

For the 7- to 12-mers, the good linearity of the $\mathrm{T}_{\mathrm{m} \text {,calc }} / \mathrm{T}_{\mathrm{m} \text {,expt }}$ relationship means that the calculated $\mathrm{T}_{\mathrm{m}}$ value is a useful predictor, relatively speaking, of duplex stability. The 5- and 6-mers do not produce as good of a linear relationship, but again, relatively speaking, the $T_{m \text {,calc }}$ does indicate relative stability with accuracy. This benchmarking is valuable since the $T_{m}$ measurement is a time-consuming experiment and if calculations are reliable, they can be used alone for predictive power.

Regarding the poorer agreement between the $T_{m \text {,calc }}$ and the $\mathrm{T}_{\mathrm{m} \text {,expt }}$ values for the 5- and 6-mers (compared with the 7- to 12-mers), the probable cause is that the 5and 6-mer duplexes are not well-formed helices [1]. The cooperative behavior of DNA formation (and melting) has a stronger driving force as the helix gets longer and, 


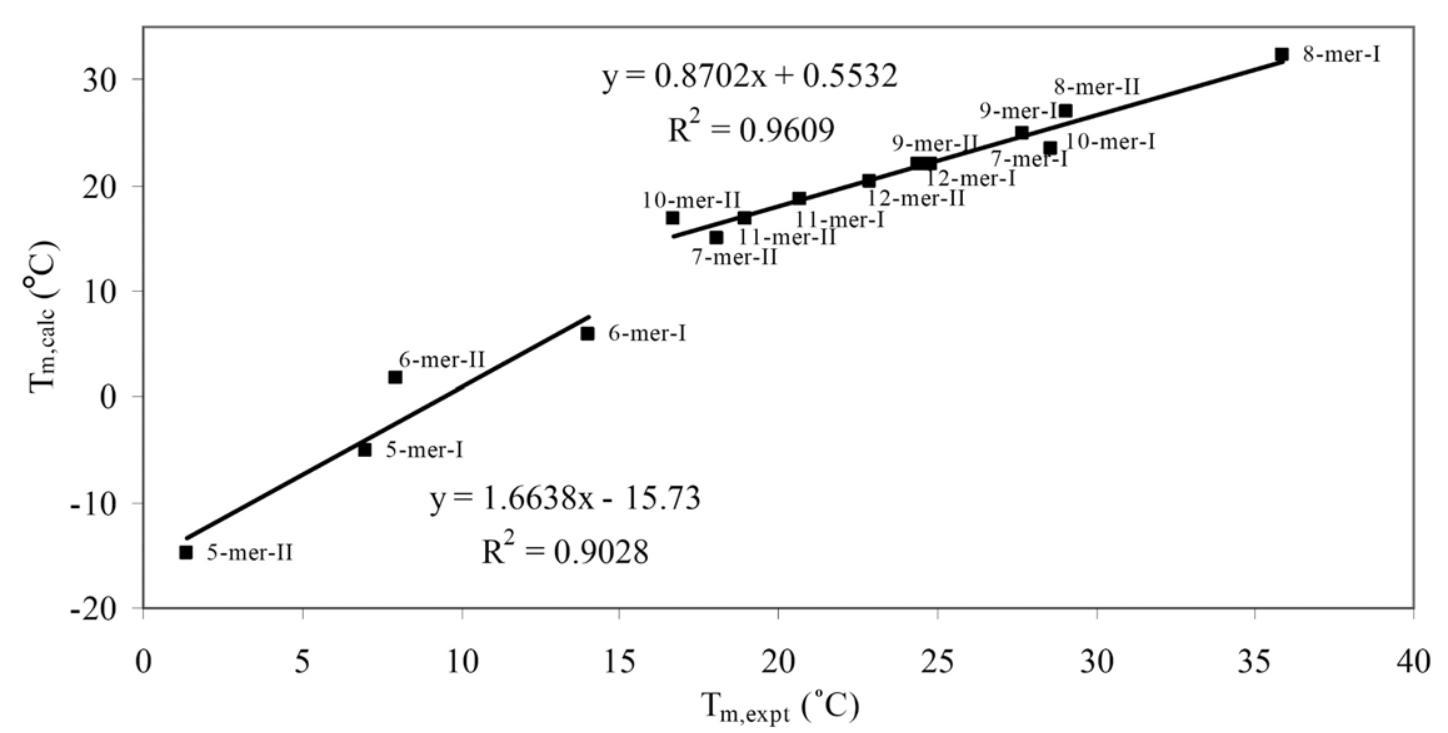

Figure 1. Correlation of calculated $T_{m}$ values $\left(T_{m, \text { calc }}\right)$ with experimental $T_{m}$ values $\left(T_{m, \text { expt }}\right)$.

therefore, shorter duplexes tend not to display as consistent behavior.

\section{Full-Scan Mass Spectrometry of DNA Duplexes}

Next, we sought to ascertain the relationship between solution phase stability and mass spectrometric ion abundance. Previous work has indicated that stronger noncovalent complexes often show a stronger mass spectrometric ion signal [13, 19, 39-41]; however, until now, such a relationship has not been quantitatively or systematically studied for DNA duplexes. In an effort to see whether such a correlation is generalizable, we examined all 16 duplexes to ascertain their gas-phase abundances upon electrospray ionization. Each duplex was therefore electrosprayed, and a "full scan" spectrum was recorded (Figure 2).

The duplex ions of the 5-mers and the 6-mers have two charge states, -3 and -2 (5-mer-I spectrum shown in Figure 2). For the 7-mers, the -3 charged duplex ions are observed nearly exclusively; 7 -mer-II produces just a minor amount of the -4 duplex. For the 8 -mers and 9-mers, two duplex charge states $(-4$ and -3$)$ are observed (8-mer-I spectrum shown in Figure 2). For the 10-mers, 11-mers, and 12-mers, the duplex ions are only observed at the -4 charge state; any duplex ions with

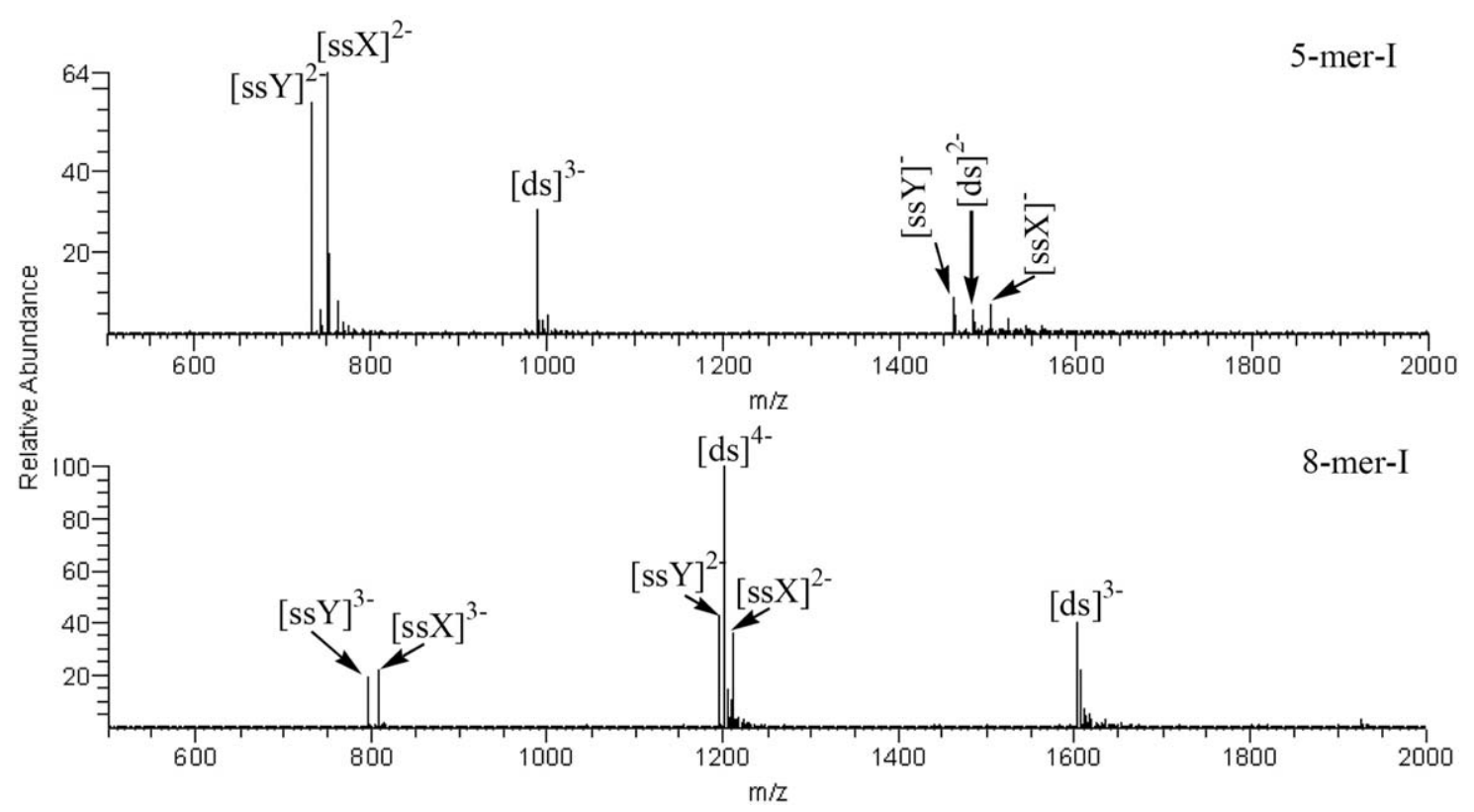

Figure 2. Full scan spectra of the 5-mer-I and 8-mer-I duplexes. Peaks corresponding to duplex ions are labeled "ds" with the corresponding charge state. Single-stranded ions are labeled "ss X" and "ssY" (see text and Table 1), with corresponding charge state. 


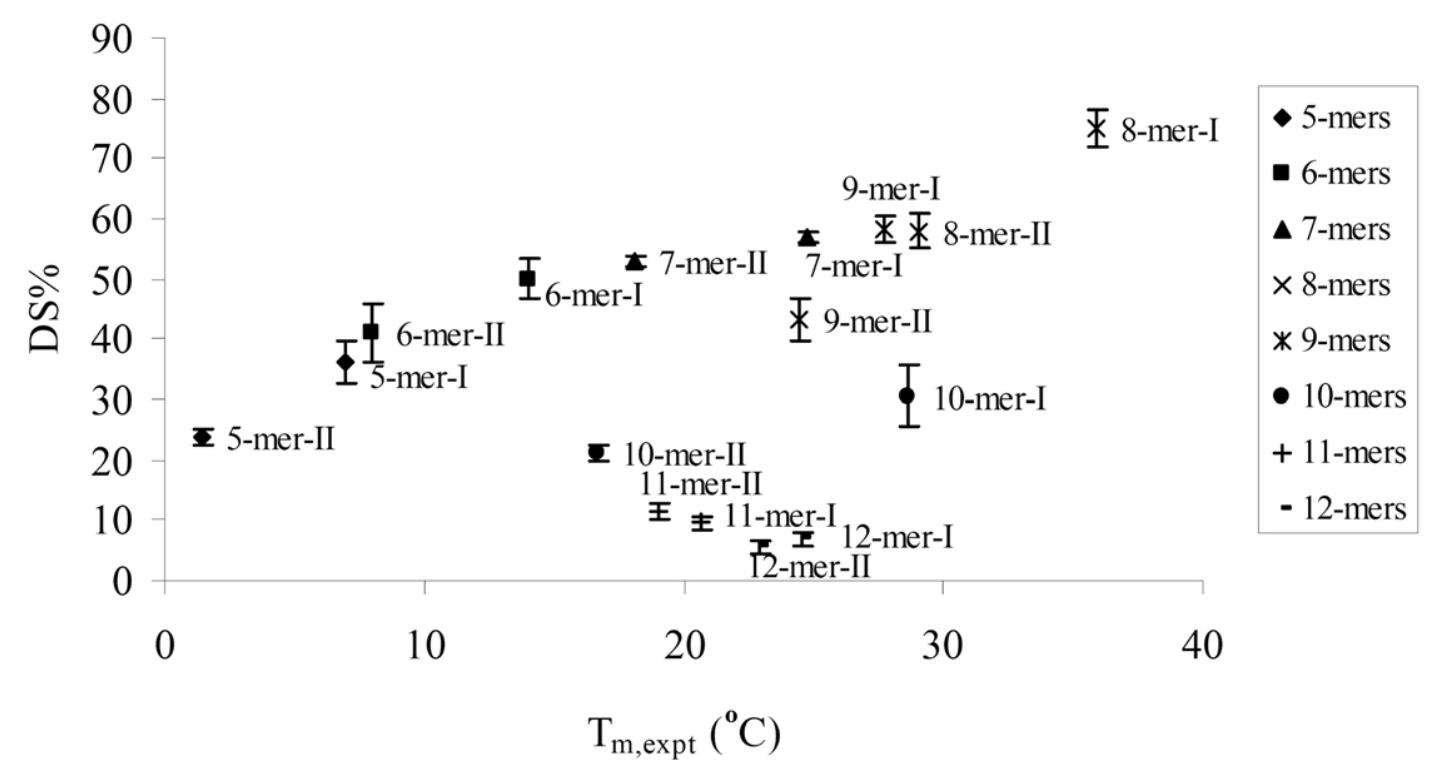

Figure 3. Normalized duplex percentage (DS\%) versus experimental melting temperature $\left(\mathrm{T}_{\mathrm{m} \text {,expt, }}\right.$ $\left.{ }^{\circ} \mathrm{C}\right)$ for the 16 duplexes examined.

lower charge states $(\mathrm{m} / \mathrm{z}>2000)$ cannot be detected due to instrumental limitations. Most likely, if there are lower charge states, they are of lower abundance than the -4 signal, since for the 5-, 6-, 8-, and 9-mer duplexes, the highest charge state is always the major peak. In each spectrum, consistent with others' results, both single strands and duplexes are detected [12, 32, $39,40,42]$. The presence of the single strands could be attributable to disruption of the duplex by the ESI process, and/or the presence of single strands in solution which then get electrosprayed and appear in the spectra; probably it is a combination of both factors (vide infra) [19].

To evaluate the correlation between the ion abundance and the solution phase composition, the normalized duplex percentages (DS\%) in the gas phase are compared with the solution phase $\mathrm{T}_{\mathrm{m}}$ values (Table 1 , Figure 3). Although this plot appears quite scattered, there are some observable trends. For the 5-mers, 5-mer I has a higher DS\%, and a higher $\mathrm{T}_{\mathrm{m} \text {,expt }}$ as well, as compared with 5-mer-II. This trend continues for each set of duplexes; that is, for the two 7-mers, a higher DS\% tracks with a higher $\mathrm{T}_{\mathrm{m} \text {,expt }}$. For the two 8-mers, again, the more stable duplex in solution has a higher DS\%. The 8-, 9-, and 10-mers also all track linearly (within each size). For the 11-mer data, the two DS\% values are within experimental error of each other; although the values track "oppositely" of the $\mathrm{T}_{\mathrm{m}}$ data, the $\mathrm{T}_{\mathrm{m}}$ values are very close as well $\left(\mathrm{T}_{\mathrm{m} \text {,calc }}\right.$ error is $\pm 1.6^{\circ} \mathrm{C}$ ) so the DS\% versus $\mathrm{T}_{\mathrm{m}}$ trend still seems to hold. The 12-mers, like the 5- to 10-mers, track with the corresponding $\mathrm{T}_{\mathrm{m}}$ values (though as with the 11-mer data, the DS\% values are within experimental error of each other). Therefore, for these data, the duplex ion abundances are a reflection of the corresponding solution phase stabilities, within a given oligonucleotide size. This conclusion is useful as it implies that duplex ion abundances could be used as a rapid assay for solution phase stability. But, why can we only compare within a given size? One of the features of our data that is related to this restriction is the strangely low DS\% values of the 10- through 12-mers. For example, 7-mer-I has a $\mathrm{T}_{\mathrm{m} \text {,expt }}$ value of $24.8^{\circ} \mathrm{C}$. The $\mathrm{DS} \%$ value is $56.9 \%$. In contrast, 12 -mer-I, which has a similar $\mathrm{T}_{\mathrm{m} \text {, expt }}$ value $\left(24.6^{\circ} \mathrm{C}\right)$, has a $\mathrm{DS} \%$ value of only $6.9 \%$. Why is it that the larger oligonucleotide has the same melting temperature value and yet a much lower DS\% value? We realized that in designing the duplexes for this study, as the oligonucleotides became longer, we decreased the GC content to keep the melting temperatures low enough to favor noncovalent dissociation of the single strands rather than fragmentation of covalent bonds (vide infra). Although it has been established that a higher GC content leads to greater solution and gas-phase stability of duplexes [11, 13-15], what we are observing here is new: that a higher GC content also affects ESI survival, and that two duplexes of equivalent stability in solution (as measured by melting temperature) may not display the same ion abundance.

To test this hypothesis, we examined a series of 8-mer duplexes (Table 2). The 8-mers were chosen because of the 16 original duplexes examined, these are extremely well behaved in that we see a strong signal at the -4 charge state.

The first set of 8-mers, A-F (Series 1), varies in GC\%, increasing from 0 to $75 \%$. The second set of 8 -mers, $\mathrm{G}$, H, J, D, K, and L (Series 2; 8-mer-D is in both sets), has a constant GC $\%$ value of $50 \%$. For the 8-mers A through $F$ (Series 1), as GC content increases, the $T_{m, \text { calc }}$ steadily increases and so too do the DS\% values (Table 2). For the latter set (Series 2), where all the duplexes have GC content of $50 \%$, the DS\% also tracks roughly with the 


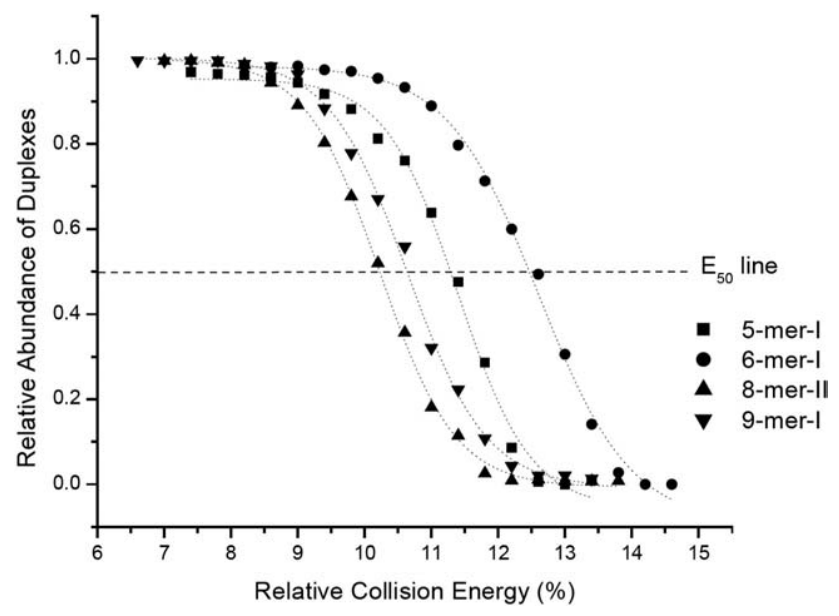

Figure 4. Gas-phase dissociation profiles of four DNA duplex ions: 5-mer-I and 6-mer-I ( -3 charge state), and 8-mer-II and 9-mer-I ( -4 charge state).

$\mathrm{T}_{\mathrm{m}, \text { calc }}$ (Table 2). However, although the duplexes in Table 2 are all 8-mers, the DS\% does not track overall with $\mathrm{T}_{\mathrm{m} \text {,calc }}$ and, as we predicted, the complicating factor is GC\%. For example, 8-mer-E has virtually the same $\mathrm{T}_{\mathrm{m} \text {,calc }}$ as 8 -mer-L $\left(25.9\right.$ versus $\left.25.4{ }^{\circ} \mathrm{C}\right)$ and yet 8-mer-E, which has a higher GC\%, also has a higher DS\% (70.5\% versus $61.1 \%)$. Likewise, 8 -mer-C has a comparable $\mathrm{T}_{\mathrm{m} \text {,calc }}$ to 8 -mer-G $\left(15.8{ }^{\circ} \mathrm{C}\right.$ and $16.1{ }^{\circ} \mathrm{C}$, respectively), yet the sequence with a higher $\mathrm{GC} \%$ (8-mer-G) has a higher DS\% (44.9\% versus $35.6 \%$ ). Therefore, using ion abundance to measure relative solution phase stability must be conducted with caution; two duplexes can have the same melting temperature, but not the same relative abundances, since sequences with higher GC\% will have a stronger signal, presumably due to better survival during ESI. We wish to stress that this is a new result; we are not merely noting that a higher GC content contributes to higher duplex stability - this is already known. Instead, we have shown that two duplexes with the exact same solution phase stability can still electrospray differentially if they have differing GC content.

It should also be noted that the DS\% value itself can change under different conditions; it is important to run all the experiments under the same conditions to get meaningful relative values [12, 13, 19, 35, 41].

\section{Gas-Phase Stability of DNA Duplexes Examined by CID}

Dissociation versus fragmentation. Having tracked the solution phase stabilities of the 16 duplexes with $\mathrm{T}_{\mathrm{m} \text {,calc }}$ $\mathrm{T}_{\mathrm{m} \text {,expt }}$ and $\mathrm{DS} \%$, we next turned toward examination of the gas-phase stability. We assess the gas-phase stability by an " $\mathrm{E}_{50}$ " value, which is the collision energy at which the duplex signal has decreased by $50 \%$ (Figure 4) [11]. This $\mathrm{E}_{50}$ is only meaningful, however, if the major pathway upon CID is dissociation of the duplex into its constitutive single strands. Unfortu- nately, upon CID, covalent fragmentation can also occur $[11,13-15,32]$. For example, CID of [5-mer-I] ${ }^{3-}$ yields all single strands (ss) as product ions; in contrast, CID of [5-mer-I] ${ }^{2-}$ results in both dissociation (to produce single strands) as well as covalent fragmentation (where a base is lost).

Our goal is to generalize the factors and patterns that control the dissociation/fragmentation relationship. Intuitively, one would expect more dissociation (and correspondingly less fragmentation) from a duplex that has more charge-Coulombic repulsion would favor the duplex separating into two strands, and indeed, this has been observed by others [11, 15]. To better examine this relationship between dissociation and charge for duplexes of different lengths and charge states, we need a measure of how much charge a duplex is carrying, regardless of its length; that is, if a long duplex carries a charge of -3 , it will have less Coulombic repulsion than a shorter duplex with the same charge. To make fair comparisons, we define and use a normalized term we coin "charge level", which is the ratio of actual charge to the total possible charge of a duplex ion [19, 43]. For example, a 5-mer duplex could hypothetically carry a total charge of -8 , so a -3 charged ion has a charge level of $3 / 8=37.5 \%$. Such a normalized value is useful for making generalizations across sets of data containing duplexes of varying lengths.

The data for the 16 duplexes is summarized in Table 3. A given path (D represents duplex dissociation, $F$ represents covalent fragmentation) is indicated if it accounts for $>5 \%$ of the products. "N/a" indicates that only one charge state is seen for the duplex, so there is no minor charge state. We have also listed the GC content (\%) of each sequence; it has been previously observed that higher GC content leads to higher gasphase stability, presumably since the $G \cdot C$ base pair has one more hydrogen bond than the A.T base pair and therefore better stabilizes the duplex [11, 13, 15, 42, 44]. A duplex with a higher GC content will therefore tend to undergo more covalent fragmentation because the two strands are more tightly bound to each other.

In an effort to assess the generalizability of charge level in comparing duplexes of different lengths, we

Table 3. Observed charge states, charge level, and CID pathway (dissociation (D) versus fragmentation $(\mathrm{F})$ ) for the sixteen 5- to 12-mer duplexes

\begin{tabular}{|c|c|c|c|}
\hline \multirow{2}{*}{$\begin{array}{l}\text { Duplex } \\
\text { length }\end{array}$} & \multirow{2}{*}{$\begin{array}{c}\% \text { of GC } \\
\text { base pairs }\end{array}$} & \multicolumn{2}{|c|}{ Charge state/Charge level (\%) } \\
\hline & & Major & Minor \\
\hline 5 & $60.0 \%$ & $-3 / 37.5 \%(D)$ & $-2 / 25.0 \%(D, F)$ \\
\hline 6 & $50.0 \%$ & $-3 / 30.0 \%$ (D) & $-2 / 20.0 \%$ (F) \\
\hline 7 & $57.1 \%$ & $-3 / 25.0 \%(F)$ & $\mathrm{n} / \mathrm{a}$ \\
\hline 8 & $62.5 \%$ & $-4 / 28.6 \%(D)$ & $-3 / 21.4 \%(F)$ \\
\hline 9 & $44.4 \%$ & $-4 / 25.0 \%(D)$ & $-3 / 18.8 \%(F)$ \\
\hline 10 & $20.0 \%$ & $-4 / 22.2 \%$ (D) & $\mathrm{n} / \mathrm{a}$ \\
\hline 11 & $9.1 \%$ & $-4 / 20.0 \%(D, F)$ & $\mathrm{n} / \mathrm{a}$ \\
\hline 12 & $8.3 \%$ & $-4 / 18.2 \%(F)$ & $\mathrm{n} / \mathrm{a}$ \\
\hline
\end{tabular}


Table 4. Charge level, GC\% and dissociation versus fragmentation results for previously studied DNA duplexes

\begin{tabular}{|c|c|c|c|c|}
\hline Entry & Sequence & $\mathrm{GC} \%$ & Charge state/level (\%) & $\mathrm{D} / \mathrm{F}$ results \\
\hline 1 & $\begin{array}{l}\text { 5' -CGTAAATTTACG-3' } \\
\text { 3'-GCATTTAAATGC-5' }\end{array}$ & $33 \%$ & $-5 / 22.7 \%$ & $\begin{array}{l}\mathrm{D}, \text { very little } \\
\mathrm{F}^{\mathrm{a}}\end{array}$ \\
\hline 2 & $\begin{array}{l}\text { 5'-CGCGAATTCGCG-3' } \\
\text { 3'-GCGCTTAAGCGC-5' }\end{array}$ & $67 \%$ & $-5 / 22.7 \%$ & $\mathrm{D}, \mathrm{F}^{\mathrm{a}}$ \\
\hline 3 & 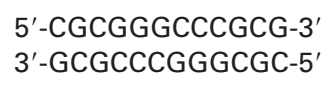 & $100 \%$ & $-5 / 22.7 \%$ & $\mathrm{~F}^{\mathrm{a}}$ \\
\hline 4 & $\begin{array}{l}5^{\prime}-\text { ATATAT-3' } \\
3^{\prime}-3^{\prime} \text { TATATA-5' }\end{array}$ & $0 \%$ & $-3 / 30 \%$ & $D^{b}$ \\
\hline 5 & 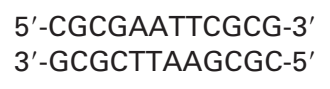 & $67 \%$ & $-5 / 22.7 \%$ & $\mathrm{D}, \mathrm{F}^{\mathrm{b}}$ \\
\hline 6 & $\begin{array}{l}5^{\prime}-\text { GCGCGC-3' } \\
3^{\prime}-\text { CGCGCG-5' }\end{array}$ & $100 \%$ & $-3 / 30 \%$ & Mostly $F^{b}$ \\
\hline
\end{tabular}

aReference [14].

${ }^{\mathrm{b}}$ Reference [11].

compare our results to earlier landmark studies. In 2002, Gabelica and De Pauw systematically examined the dissociation of a series of 12-mer duplexes under different collision regimes [14]. Using the LCQ, under the same conditions as we use (activation time $=30$ $\mathrm{ms}$ ), these authors also see varying amounts of dissociation versus fragmentation depending on sequence (first three entries, Table 4). All 12-mers have a charge state of -5 , which corresponds to a charge level of $22.7 \%$. For the sequence 5'-CGTAAATTTACG-3' /3'GCATTTAAATGC-5', which has 33\% GC, Gabelica and De Pauw see mostly D, with a small amount of F. Our 10 -mers have a lower GC\% (20\%), but a comparable charge level (22.2\%) (Table 3, "major" column); since our GC content is lower, we would expect dissociation to be as or even more favorable, relatively speaking, than for Gabelica's 12 mer, and in fact we do see essentially all D (Table 3).

The second 12-mer examined by Gabelica and De Pauw is 5'-CGCGAATTCGCG-3' /3'-GCGCTTAAGCGC-5', which is $67 \%$ GC and for which the authors see both D and F. The most comparable duplexes in our study would be the 5-mers, which have $60 \%$ GC (Table 3 ). The minor charge state for our 5-mers, -2 , has a comparable charge level $(25.0 \%)$ to that of the Gabelica 12-mer $(22.7 \%)$ and our results are consistent: we see both $D$ and $\mathrm{F}$.

The third 12-mer that Gabelica and De Pauw studied is $5^{\prime}$-CGCGGGCCCGCG-3' /3'-GCGCCCGGGCGC-3', which has a GC\% of $100 \%$ and for which the authors see only F; we have no duplex with such high GC\% for comparison.

We also list in Table 4 three sequences examined in 2000 by Gross and coworkers using, as we do, CID in a quadrupole ion trap [11]. The first duplex, a 6-mer with the sequence 5'-ATATAT-3' /3'-TATATA-5', has zero GC content and a charge level of $30 \%$, and only D is observed. We have no duplex with such a low GC content and high charge level, but our 6-mers have even higher GC content
(50\%) and the same charge level, and only D is observed, consistent with Gross' work. Clearly, the high charge level favors dissociation even though the GC content in our duplex is higher. The second duplex examined by Gross and coworkers is a 12-mer, 5'-CGCGAATTCGCG-3' / $5^{\prime}$ GCGCTTAAGCGC-3', which is actually the same duplex examined by Gabelica and coworkers (entry no. 2, Table 4); Gross' results are consistent with Gabelica's and ours. Gross and coworkers also examined a second 6-mer, with the sequence 5'-GCGCGC-3' /3'-CGCGCG-5'. The GC content of this duplex is $100 \%$, and the authors observe "quite abundant product ions by cleavage of covalent bonds" (F) [11]. This result is consistent with Gabelica's 12-mer 5'-CGCGGGCCCGCG-3'/3'-GCGCCCGGGCGC-5' (Table 4, entry no. 3), which also has 100\% GC; although the charge level is lower, Gabelica also sees $\mathrm{F}$ as the major pathway, presumably due to the $100 \%$ GC content.

To summarize, we have shown that by using charge level, we can compare duplexes that differ in sequence, size, and charge state. In doing so, we find that our results are consistent with earlier studies, and that the previous studies are also consistent with each other. Charge level is therefore a useful method by which we can normalize charge effects, and we plan to conduct systematic future studies to quantitate "crossover" charge level and GC content points where dissociation or fragmentation prevail [45].

We also note that while there are other studies that have examined dissociation versus fragmentation of DNA duplexes, we only compare our results with other CID-quadrupole ion trap studies that use the same collision conditions as we do; Gabelica and De Pauw have shown the importance of considering collision regimes, since fast activation conditions favor dissociation [14]. For example, the duplex in entry no. 2 (Table 4) exhibits very little fragmentation when Q-TOF2 is used [14]. 
Table 5. CID data for additional 6-mers (-3)

\begin{tabular}{|c|c|c|c|c|}
\hline Duplex Name & Sequence (ssX \& ssY) & GC\% & $\mathrm{T}_{\mathrm{m}, \text { calc }}\left({ }^{\circ} \mathrm{C}\right)$ & $E_{50}(\%)$ \\
\hline 6-mer-A & $\begin{array}{l}5^{\prime}-\mathrm{AGAGAG}-3^{\prime} \\
3^{\prime}-\mathrm{TCTCTC}-5^{\prime}\end{array}$ & 50 & -4.1 & $12.83 \pm 0.06$ \\
\hline 6-mer-B & $\begin{array}{l}5^{\prime}-\mathrm{GTCTGT}-3^{\prime} \\
3^{\prime}-\mathrm{CAGACA}-5^{\prime}\end{array}$ & 50 & 0.2 & $12.12 \pm 0.05$ \\
\hline 6-mer-II & $\begin{array}{l}5^{\prime} \text {-GTGTCA-3' } \\
3^{\prime} \text {-GACTCT-5' }\end{array}$ & 50 & 1.8 & $12.75 \pm 0.10$ \\
\hline 6-mer-C & $\begin{array}{l}5^{\prime}-\mathrm{GTGTGT}-3^{\prime} \\
3^{\prime}-\mathrm{CACACA}-5^{\prime}\end{array}$ & 50 & 2.8 & $12.26 \pm 0.05$ \\
\hline 6-mer-D & $\begin{array}{l}5^{\prime}-\text { TGTGTG-3' } \\
3^{\prime} \text {-ACACAC-5' }\end{array}$ & 50 & 2.9 & $12.19 \pm 0.06$ \\
\hline 6-mer-I & $\begin{array}{l}5^{\prime}-\text { GCGAAT-3' } \\
\text { 3'-CGCTTA-5' }\end{array}$ & 50 & 5.9 & $12.57 \pm 0.10$ \\
\hline
\end{tabular}

Gas-phase stability $\left(E_{50}\right)$ versus solution phase stability $\left(T_{m}\right)$. To next focus on duplex gas-phase stabilities, we chose those duplexes that undergo dissociation only, so that we can use $\mathrm{E}_{50} \mathrm{~s}$ meaningfully. The only duplex that shows exclusive dissociation but is not discussed here is the 10-mer series, for which we had experimental issues with obtaining the CID curve; we observe severe "tailing" wherein the duplex signal persists, even at high collision energies.

The $\mathrm{E}_{50} \mathrm{~s}$ for the 5-, 6-, 8-, and 9-mer duplexes are listed in Table 1. Our interest is to compare and contrast the gas and solution phase stabilities. A higher $\mathrm{E}_{50}$ value indicates a more stable duplex in the gas phase. Therefore, in the gas phase, 5 -mer-I $\left(\mathrm{E}_{50}=11.48 \%\right)$ is more stable than 5-mer-II $\left(\mathrm{E}_{50}=11.22 \%\right)$; 8-mer-I $\left(\mathrm{E}_{50}=\right.$ $10.53 \%)$ is more stable than 8 -mer-II $\left(\mathrm{E}_{50}=10.27 \%\right)$; and 9-mer-I $\left(\mathrm{E}_{50}=10.61 \%\right)$ is more stable than 9-mer-II $\left(\mathrm{E}_{50}\right.$ $=10.50 \%$ ). These relative trends are consistent with the solution phase trends; that is, the N-mer-I duplexes have higher $\mathrm{T}_{\mathrm{m} \text {,expt }} \mathrm{s}$ than do the N-mer-II duplexes. An exception to the $\mathrm{E}_{50} / \mathrm{T}_{\mathrm{m} \text {,expt }}$ correlation is the stability trends for 6-mer-I and 6-mer-II. The gas-phase stability of 6 -mer-I $\left(\mathrm{E}_{50}=12.57 \%\right)$ is less than that of 6 -mer-II $\left(\mathrm{E}_{50}=12.75 \%\right)$. In contrast, the $\mathrm{T}_{\mathrm{m}}$ and DS\% of $6-\mathrm{mer}-\mathrm{I}$ are higher than those of 6-mer-II, indicating that the 6-mer-I duplex is more stable than 6-mer-II in solution. A reversal in gas-phase stability versus solution-phase stability in complementary duplexes has been observed once earlier, to our knowledge, by Gabelica and coworkers; in a study of four 16-mer duplexes with $50 \%$ GC content, they found that the gas-phase stability of one duplex did not parallel its calculated solution-phase stability [15]. These authors hypothesize that the sequence of the "misbehaving" duplex, which has four $\mathrm{A}^{\prime} \mathrm{s}$ in a row, is distorted due to this A-tract, causing problems with the calculated solution phase stability and also possibly leading to reduced gas-phase stability.

We found our result puzzling as we do not expect either of the 6-mers to have a distorted structure. Exceptions in gas-phase versus solution-phase trends such as these are of primary interest to us as they imply that solvation plays a role in reversing the stabilities. We also believe that these exceptions are not that uncommon: we have found with a series of 9-mer duplexes that are both complementary and noncomplementary (with mismatches), that gas and solution phase stabilities can often differ; our studies indicate that the differences can be traced to the fact that stacking predominates in solution while hydrogen bonding dominates in the gas phase [19].

We hypothesize that with complementary duplexes such as the ones studied herein, the gas/solution phase correlation is less reliable when the GC content is the same among the studied duplexes. When the GC percentage is constant in a series of duplexes, then hydrogen bonding effects should be similar, and any differences in stability will be attributable to stacking. Stacking is a strong and well-understood force in solution, (which is the basis for nearest-neighbor predictions of stability), but it is a relatively weaker force in the gas phase and has not yet been systematically examined [15, 28-31, 37, 38]. Hydrogen bonding dominates in the gas phase; therefore, if one studies a series of duplexes with differing GC content, the gas-phase stabilities will track with the increasing GC content. Hydrogen bonding is still a strong force in solution and, therefore, the gas and solution phase stabilities tend to parallel each other.

To test this hypothesis, we studied several more 6-mers and 8-mers. The 6-mers were chosen since it is within this set that we saw the gas/solution phase exception. The 8-mers were chosen because of the original 16 duplexes examined, these are very well behaved; we see a strong signal at the -4 charge state, and CID produces minimal covalent fragmentation.

The 6-mers were designed to maintain the same (50\%) GC content (Table 5 and Figure 5). Based on our hypothesis, we would expect these 6-mers not to have a clear linear correlation between gas and solution phase stabilities. Indeed, the 6-mer data are listed in increasing $\mathrm{T}_{\mathrm{m} \text {,calc }}$ value in Table 5; it is quite clear that the $\mathrm{E}_{50}$ 


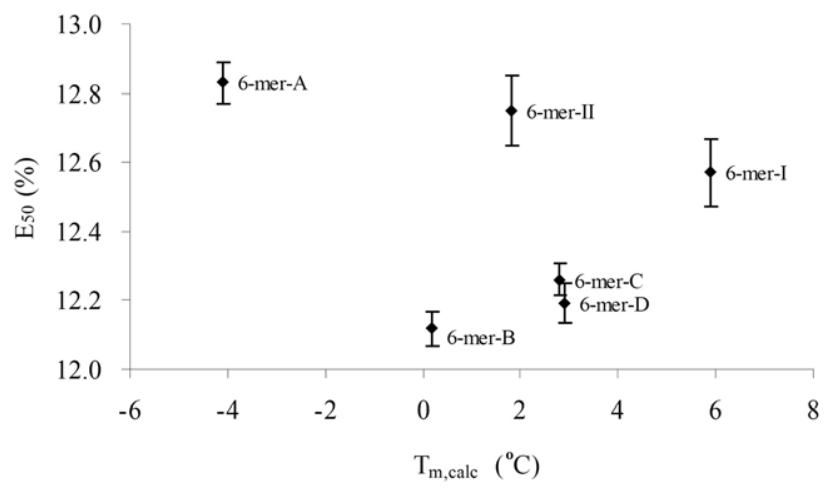

Figure 5. Plot of gas-phase stabilities $\left(\mathrm{E}_{50}\right)$ versus solution phase stabilities $\left(\mathrm{T}_{\mathrm{m} \text {,expt }}\right)$ for six 6-mer duplexes (see Table 5).

values do not increase correspondingly and Figure 5 shows a scattered plot. As we predicted, when the GC content is held constant, stacking dictates differences in stability, and apparently these factors differ in solution than in the gas phase.

For the additional 8-mer studies, we used the same duplexes that were examined in the DS\% studies. Eight-mers A-F constitute "Series 1", which have varying GC content (Table 2). Eight-mers G, H, J, D, K, and L (D appears in both series) constitute "Series 2", which all have a GC content of 50\% (Table 2). By our hypothesis, we predict that Series 1 would yield a clear gas-solution phase correlation, since the GC content varies. For Series 2, where all the duplexes have the same GC content, we expect no correlation, as we observed with the 6-mers.

The Series 1 8-mer data are listed in Table 2 and Figure 6 . The data are listed in Table 2 by increasing $\mathrm{GC} \%$, which also correspond to increasing $\mathrm{T}_{\mathrm{m} \text {,calc }}$ (8mer-A produced too weak of a duplex signal to conduct reproducible CID studies). One can see that the $\mathrm{E}_{50}$ values also increase and a plot of the data $\left(E_{50}\right.$ versus $\left.\mathrm{T}_{\mathrm{m} \text {,calc }}\right)$, while not perfectly linear, shows a clear gassolution phase correlation (Figure 6). The Series 2 data are also listed in Table 2; the duplexes are ordered in increasing $\mathrm{T}_{\mathrm{m} \text {,calc }}$ values. As predicted, the $\mathrm{E}_{50}$ values do

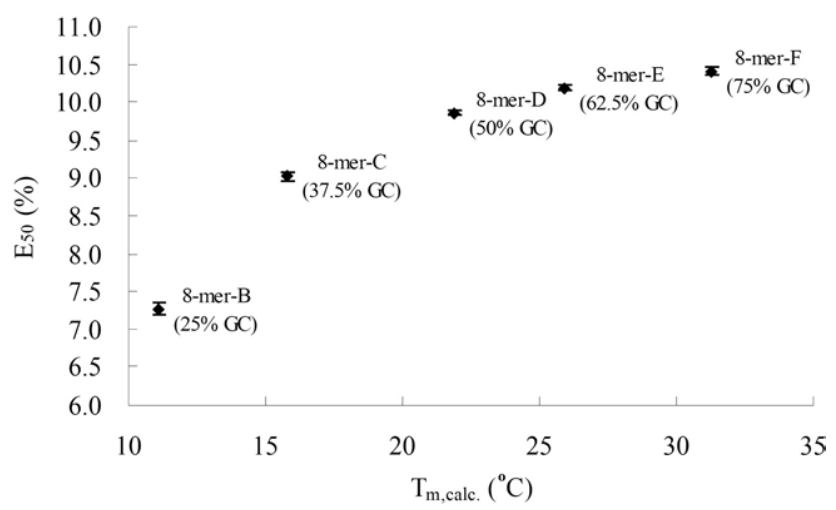

Figure 6. Plot of gas-phase stabilities $\left(\mathrm{E}_{50}\right)$ versus solution phase stabilities $\left(\mathrm{T}_{\text {m,expt }}\right)$ for "Series 1" 8-mer duplexes, which have varying GC content (see Table 2 ).

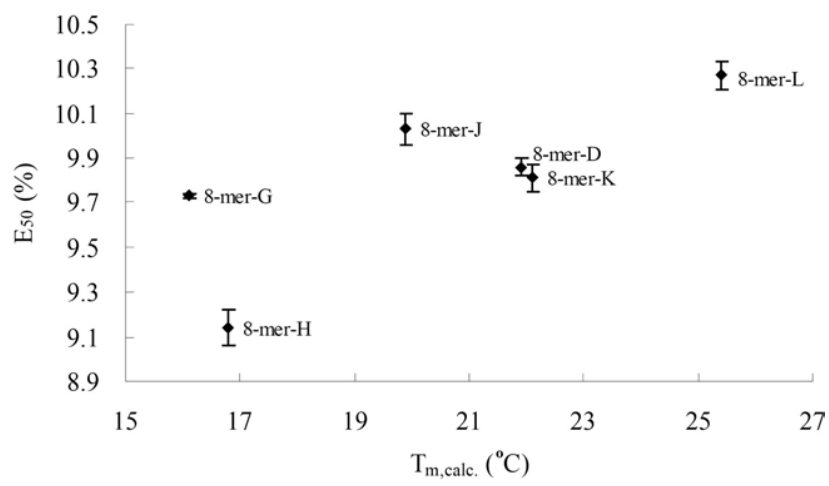

Figure 7. Plot of gas-phase stabilities $\left(\mathrm{E}_{50}\right)$ versus solution phase stabilities $\left(\mathrm{T}_{\mathrm{m}, \text { expt }}\right)$ for "Series 2" 8-mer duplexes, all of which have $50 \%$ GC content (see Table 2).

not increase accordingly, and the plotted data is quite scattered (Figure 7).

Therefore, apparently our hypothesis holds true: when duplexes have the same GC content, the gas and solution phase behavior does not always correlate because relative stacking differs in the nonpolar versus polar media. If GC content does vary, then the strong hydrogen bonding forces result in parallel (though not always perfectly linear) behavior in the gas phase versus solution. This hypothesis holds for earlier studies as well. In the 2002 study containing the gas/ solution exception, Gabelica and De Pauw only compared duplexes that contained the same GC content (since they were interested in focusing on stacking effects) [15]. Two duplexes with $25 \%$ content are compared; the duplex with the higher gas-phase stability also has a higher calculated solution-phase stability (as indicated by computed melting enthalpy). As noted earlier in this section, when four duplexes with 50\% GC content are compared, three show a parallel gas-phase/ solution-phase trend, but one does not. When three duplexes of $75 \%$ GC are compared, the gas and solution phase stabilities correlate. We argue that the exception that is seen with the $50 \%$ GC duplexes is not unusual; as one compares more duplexes with the same size, charge, and GC content, one is bound to find, as we did, differences in gas versus solution phase stabilities. Stacking interactions may still be conserved in the gas-phase, but their relative "worth" may change in the highly nonpolar environment.

In another study, Gabelica and De Pauw tracked the solution versus gas-phase stability of a series of 16-mers that differ in GC content [13]. To visualize their results, we plotted their data and found, in accord with our hypothesis, that the gas/solution phase correlation for these duplexes with varying GC content is definitively linear.

Clearly, base stacking is a property that differs quite substantially in the gas phase versus in solution; future studies will focus on understanding gas-phase base stacking effects. 


\section{Biomedical Application: The Gas-Phase Stability of DNA Duplexes Containing Mutagenic Lesions}

One of the driving forces for our studies of DNA duplex stability is to understand the effects of damaged bases. The main question we wish to answer is, how does the presence of a damaged base affect the stability of DNA? One of our focuses is the $\mathrm{O}^{6}$-methylguanine lesion, which is produced in DNA by alkylating agents and is believed to be fundamental to the mutagenicity and carcinogenicity of such agents. When an oligodeoxynucleotide containing OMG is inserted into a viral or plasmid genome, the OMG causes a $\mathrm{G} \rightarrow \mathrm{A}$ transition exclusively $[20-22,24,25]$. That is, guanine in a healthy duplex binds cytosine. When guanine mutates to OMG and the duplex replicates, the DNA polymerase enzyme puts a thymine opposite OMG - that is, OMG prefers to bind to $\mathrm{T}$ during replication. The strand with thymine will replicate and ultimately pair with an adenine; thus the OMG mutation is referred to as a $G \rightarrow A$ transition.

Although the strong preference after OMG damage for the $G \rightarrow$ A transition implies that OMG preferentially pairs to thymine over cytosine [46-48] in solution, studies on duplexes containing OMG indicate that the (OMG).C pair is more stable than the (OMG).T pair, regardless of the sequence $[26,49,50]$. Thus, $\mathrm{OMG}$ prefers $C$ in aqueous solution, but in biological replication, the enzyme DNA polymerase incorporates a T opposite OMG. The reasons for this could be structural-the (OMG).T pair may "fit" better into the enzyme active site. However, because enzyme active sites are often nonpolar, reactivity can be markedly different than in aqueous solution $[7,9]$. We wondered if perhaps in a nonpolar environment, OMG might prefer $T$ over $C$. As a test of this possibility, the gas-phase stabilities of DNA duplexes containing $(\mathrm{OMG}) \cdot \mathrm{C}$ and $(\mathrm{OMG}) \cdot \mathrm{T}$ could be compared. The gas phase is the ultimate nonpolar environment and would indicate the intrinsic affinity of $O M G$ for $C$ versus $T$.

We examined a series of 9-mer duplexes of the sequence 5'-GGTTXTTGG-3' /3'-CCAAYAACC-5', where $\mathrm{X}=\mathrm{OMG}$ and $\mathrm{Y}=\mathrm{C}$ or $\mathrm{T}$; and $\mathrm{Y}=\mathrm{OMG}, \mathrm{X}=\mathrm{C}$ or $\mathrm{T}$. This particular sequence has been well characterized in solution phase OMG studies; furthermore, our present studies on duplexes of varying length indicate consistent behavior of 9-mers in CID studies [26]. Also, based on the results of the systematic study, we wanted a series of duplexes that were related and had roughly the same GC content, since we wished to assess the gas-phase stability. We refer to

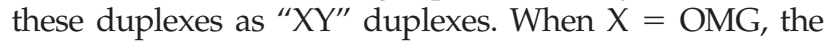
$\mathrm{E}_{50}$ values of the (OMG)C and (OMG)T duplexes are 8.91 $\pm 0.06 \%$ and $8.48 \pm 0.05 \%$. Therefore, the $(\mathrm{OMG}) \mathrm{C}$ duplex is more stable than $(\mathrm{OMG}) \mathrm{T}$ in the gas phase. In the duplexes where $\mathrm{Y}=\mathrm{OMG}$, the $\mathrm{E}_{50}$ values of the $\mathrm{C}(\mathrm{OMG})$ and $\mathrm{T}(\mathrm{OMG})$ duplexes are $8.61 \pm 0.03 \%$ and $8.47 \pm 0.04 \%$. The $\mathrm{C}(\mathrm{OMG})$ duplex is thus more stable than $\mathrm{T}(\mathrm{OMG})$ in the gas-phase. In essence, for the sequences examined, duplexes containing an (OMG).C base pair are more stable than those with an (OMG).T pair, which is the same behavior observed in aqueous solution. Therefore, the stability of the duplex, regardless of the medium, is in direct disagreement with what happens in Nature, thus implying that the polymerase enzyme plays a specific role in recognizing and favoring the pairing of OMG with $\mathrm{T}$.

\section{Conclusions}

Understanding the features of electrosprayed oligonucleotides is important both for fundamental (how does solvent affect DNA structure and stability?) as well as applied reasons (how does DNA gas-phase behavior impact MS sequencing, screening, and assay studies?).

In this work, a series of 31 duplexes, ranging in size from 5- to 12-mers, was examined. To our knowledge, this is the first systematic study of a set of duplexes that differ in sequence and size, to establish both solution and gas-phase stabilities.

We have shown that the computational program MELTING does not always give accurate absolute melting temperatures, but is a reliable tool for predicting relative solution phase stabilities; this calculational tool is a useful, efficient replacement for traditional UV melting temperature experiments.

We have found that ion abundances do not always track with solution phase stability; GC content must be taken into account. Two duplexes with the same $T_{m}$ yet with differing GC content can yield different ion abundances. That is, if two duplexes have the exact same melting temperature, yet one has a higher GC content, the duplex with the higher GC content yields a higher ion abundance. This result is tantalizing in that it indicates that the gas phase can be different from the solution phase; it is not just a matter of GC providing more stability than AT-what we see is that two duplexes of the same stability do not electrospray equally if they have differing GC content.

We also examined the factors contributing to dissociation (into single strands) versus fragmentation (covalent bond breakage) in the CID studies of the duplexes. Our utilization of a normalization that we call "charge level" leads to a consistent story in dissociation versus fragmentation for duplexes studied by us as well as others, regardless of length, sequence, or charge state. Charge level and GC content work together to dictate dissociative behavior, and future studies will involve finding exact crossover points in terms of how these two features balance each other out.

We also examined those duplexes that primarily dissociate and used CID to assess the gas-phase stabilities. We find that gas-phase and solution-phase stabilities are more apt to parallel each other if the GC content is varied. When the GC content is kept constant, base stacking dictates stability and our results show that base stacking appears to be quite different in the gas-phase than in solution. Our interpretation enables us to bring previous data and our results into a consistent, understandable story. Future studies will involve 
the elucidation of base stacking patterns in the gas phase.

Last, we used our methodology to design an experiment to ascertain whether $\mathrm{O}^{6}$-methylguanine (OMG) prefers thymine or cytosine in the gas phase; in nature, its preference for thymine is deleterious. We wished to assess whether OMG has an intrinsic preference for thymine in the absence of solvent. The relevance of the reactivity of OMG in the gas phase is because the polymerase enzyme active site may be nonpolar; this nonpolar environment may induce a shift in OMG's base pairing preferences. We find that for the 9-mer sequence we studied, in the gas phase, as in solution, OMG actually prefers cytosine; therefore, the pairing of OMG with thymine in nature is effected by the polymerase enzyme through specific interactions, not that of general nonpolarity of media.

\section{Acknowledgments}

The authors are grateful to Professor Ken Breslauer, Dr. Barbara Gaffney, and Professor Roger Jones for providing the equipment necessary for the melting temperature experiments. They also thank the National Science Foundation (CHE-0092215, CHE-0543038), the Alfred P. Sloan Foundation, and the Rutgers Busch Grant Program for support, and the National Center for Supercomputing Applications for computational resources.

\section{References}

1. Saenger, W. Principles of Nucleic Acid Structure; Springer-Verlag: New York, NY, 1984; pp 116-158.

2. Brown, T. Mismatches and Mutagenic Lesions in Nucleic Acids. Aldrichimica Acta 1995, 28, 15-20.

3. Smith, R. D.; Bruce, J. E.; Wu, Q.; Lei, Q. P. New Mass Spectrometric Methods for the Study of Noncovalent Associations of Biopolymers. Chem. Soc. Rev. 1997, 26, 191-202.

4. Daniel, J. M.; Friess, S. D.; Rajagopalan, S.; Wendt, S.; Zenobi, R. Quantitative Determination of Noncovalent Binding Interactions Using Soft Ionization Mass Spectrometry. Int. J. Mass Spectrom. 2002, 216, 1-27.

5. Gabelica, V.; Galic, N.; Rosu, F.; Houssier, C.; De Pauw, E. Influence of Response Factors on Determining Equilibrium Association Constants of Noncovalent Complexes by Electrospray Ionization Mass Spectrometry. J. Mass Spectrom. 2003, 38, 491-501.

6. McLafferty, F. W. Tandem Mass Spectrometry. Science 1981, 214, 280 287.

7. Jordan, F.; Li, H.; Brown, A. Remarkable Stabilization of Zwitterionic Intermediates May Account for a Billionfold Rate Acceleration by Thiamin Diphosphate-Dependent Decarboxylases. Biochemistry 1999, $38,6369-6373$.

8. Simonson, T.; Brooks, C. L. III. Charge Screening and the Dielectric Constant of Proteins: Insights from Molecular Dynamics. J. Am. Chem. Soc. 1996, $118,8452-8458$

9. Kurinovich, M. A.; Lee, J. K. The Acidity of Uracil from the Gas Phase to Solution: The Coalescence of the N1 and N3 Sites and Implications for Biological Glycosylation. J. Am. Chem. Soc. 2000, 122, 6258-6262.

10. Doktycz, M. J.; Habibi-Goudarzi, S.; McLuckey, S. A. Accumulation and Storage of Ionized Duplex DNA Molecules in a Quadrupole Ion Trap. Anal. Chem. 1994, 66, 3416-3422.

11. Wan, K. X.; Gross, M. L.; Shibue, T. Gas-Phase Stability of DoubleStranded Oligodeoxynucleotides and their Noncovalent Complexes with DNA-Binding Drugs as Revealed by Collisional Activation in an Ion Trap. J. Am. Soc. Mass Spectrom. 2000, 11, 450-457.

12. Gabelica, V.; Rosu, F.; Houssier, C.; De Pauw, E. Gas Phase Thermal Denaturation of an Oligonucleotide Duplex and Its Complexes with Minor Groove Binders. Rapid Commun. Mass Spectrom. 2000, 14, 464467.

13. Gabelica, V.; De Pauw, E. Comparison Between Solution-Phase Stability and Gas-Phase Kinetic Stability of Oligodeoxynucleotide Duplexes. J. Mass Spectrom. 2001, 36, 397-402.

14. Gabelica, V.: De Pauw, E. Comparison of the Collision-Induced Dissociation of Duplex DNA at Different Collision Regimes: Evidence for a Multistep Dissociation Mechanism. J. Am. Soc. Mass Spectrom. 2002, 13, 91-98.
15. Gabelica, V.; De Pauw, E. Collision-Induced Dissociation of 16-mer DNA Duplexes with Various Sequences: Evidence for Conservation of the Double Helix Conformation in the Gas Phase. Int. J. Mass Spectrom. 2002, 219, 151-159.

16. Gidden, J.; Baker, E. S.; Ferzoco, A.; Bowers, M. T. Structural Motifs of DNA Complexes in the Gas Phase. Int. J. Mass Spectrom. 2005, 240, 183-193.

17. Wyttenbach, T.; Baker, E. S.; Bernstein, S. L.; Ferzoco, A.; Gidden, J.; Liu, D.; Bowers, M. T. The Ion Mobility Mass Spectrometry and Its Application to Duplex Formation of Oligonucleotides and Aggregation of Proteins. Adv. Mass Spectrom. 2004, 16, 189-200.

18. Yang, M.; Thompson, R.; Hall, G. Comparative Stability Determination of Oligonucleotide Duplexes in Gas and Solution Phase. J. Am. Soc. Mass Spectrom. 2004, 15, 1354-1359.

19. Pan, S.; Sun, X.; Lee, J. K. Stability of Complementary and Mismatched DNA Duplexes: Comparison and Contrast in Gas Versus Solution Phases. Int. J. Mass Spectrom. 2006, 253, 238-248.

20. Loechler, E. L.; Green, C. L.; Essigmann, J. M. In Vivo Mutagenesis by $\mathrm{O}^{6}$-Methylguanine Built into a Unique Site in a Viral Genome. Proc. Natl. Acad. Sci. U.S.A. 1984, 81, 6271-6275.

21. Chambers, R. W.; Sledziewska-Gojska, E.; Hirani-Hojatti, S.; BorowyBorowski, H. uvrA and recA Mutations Inhibit a Site-Specific Transition Produced by a Single $\mathrm{O}^{6}$-Methylguanine in Gene G of Bacteriophage FX174. Proc. Natl. Acad. Sci. U.S.A. 1985, 82, 7173-7177.

22. Bhanot, O. S.; Ray, A. The In Vivo Mutagenic Frequency and Specificity of $\mathrm{O}^{6}$-Methylguanine in $\phi X 174$ Replicative Form DNA. Proc. Natl. Acad. Sci. U.S.A. 1986, 83, 7348-7352.

23. Zarbl, H.; Sukumar, S.; Arthur, A. V.; Martin-Zanca, D.; Barbacid, M. Direct Mutagenesis of Ha-ras-1 Oncogenes by N-Nitroso-N-Methylurea During Initiation of Mammary Carcinogenesis in Rats. Nature 1985, 315, 382-385.

24. Topal, M. D.; Eadie, J. S.; Conrad, M. $\mathrm{O}^{6}$-Methylguanine Mutation and Repair is Nonuniform. Selection for DNA Most Interactive with $\mathrm{O}^{6}$ Methylguanine. J. Bio. Chem. 1986, 261, 9879-9885.

25. Hill-Perkins, M.; Jones, M. D.; Karran, P. Site-Specific Mutagenesis In Vivo by Single Methylated or Deaminated Purine Bases. Mutat. Res. 1986, 162, 153-163.

26. Gaffney, B. L.; Jones, R. A. Thermodynamic Comparison of the Base Pairs Formed by the Carcinogenic Lesion $\mathrm{O}^{6}$-Methylguanine with Reference Both to Watson-Crick Pairs and to Mismatched Pairs. Biochemistry 1989, 28, 5881-5889.

27. Lips, J.; Kaina, B. Repair of $\mathrm{O}^{6}$-Methylguanine is Not Affected by Thymine Base Pairing and the Presence of MMR Proteins. Mutat. Res. 2001, 487, 59-66.

28. Le Novere, N. MELTING, Computing the Melting Temperature of Nucleic Acid Duplex. Bioinformatics 2001, 17, 1226-1227.

29. (a) SantaLuciaJ., Jr.; Allawi, H. T.; Seneviratne, P. A. Improved NearestNeighbor Parameters for Predicting DNA Duplex Stability. Biochemistry 1996, 35, 3555-3562; (b) Owczarzy, R.; You, Y.; Moreira, B. G.; Manthey, J. A.; Huang, L.; Behlke, M. A.; Walder, J. A. Effects of Sodium Ions on DNA Duplex Oligomers: Improved Predictions of Melting Temperatures. Biochemistry 2004, 43, 3537-3554.

30. SantaLucia, J., Jr.; Hicks, D. The Thermodynamics of DNA Structural Motifs. Annu. Rev. Biophys. Biomol. Struct. 2004, 33, 415-440.

31. SantaLucia, J., Jr. A Unified View of Polymer, Dumbbell, and Oligonucleotide DNA Nearest-Neighbor Thermodynamics. Proc. Natl. Acad. Sci. U.S.A. 1998, 95, 1460-1465.

32. Wan, K. X.; Shibue, T.; Gross, M. L. Noncovalent Complexes Between DNA-Binding Drugs and Double-Stranded Oligodeoxynucleotides: A Study by ESI Ion-Trap Mass Spectrometry. J. Am. Chem. Soc. 2000, 122, 300-307.

33. Lopez, L. L.; Tiller, P. R.; Senko, M. W.; Schwartz, J. C. Automated Strategies for Obtaining Standardized Collisionally Induced Dissociation Spectra on a Benchtop Ion Trap Mass Spectrometer. Rapid Commun. Mass Spectrom. 1999, 13, 663-668.

34. Deschenes, L. A.; Vanden Bout, D. A. Origin 6.0: Scientific Data Analysis and Graphing Software Origin Lab Corporation (formerly Microcal Software, Inc.). J. Am. Chem. Soc. 2000, 122, 9567-9568.

35. Pan, S.; Lee, J. K. Electrospray Mass Spectrometry of Complementary and Mismatched DNA Duplexes. Proceedings of the 50th ASMS Conference on Mass Spectrometry and Allied Topics; Orlando, FL, 2002.

36. Michelson, A. M. Hypochromicity of Oligo- and Polynucleotides. Biochim. Biophys. Acta 1962, 55 841-848.

37. Breslauer, K. J.; Frank, R.; Blöcker, H.; Marky, L. A. Predicting DNA Duplex Stability from the Base Sequence. Proc. Natl. Acad. Sci. U.S.A. 1986, 83, 3746-3750.

38. Sugimoto, N.; Nakano, S.; Yoneyama, M.; Honda, K. Improved Thermodynamic Parameters and Helix Initiation Factor to Predict Stability of DNA Duplexes. Nucleic Acids Res. 1996, 24, 4501-4505.

39. Ganem, B.; Li, Y.-T.; Henion, J. D. Detection of Oligonucleotide Duplex Forms by Ion-Spray Mass Spectrometry. Tetrahedron Lett. 1993, 34, 1445-1448.

40. Ding, J.; Anderegg, R. J. Specific and Nonspecific Dimer Formation in the Electrospray Ionization Mass Spectrometry of Oligonucleotides. J. Am. Soc. Mass Spectrom. 1995, 6, 159-164.

41. Greig, M. J.; Gaus, H.-J.; Griffey, R. H. Negative Ionization Micro Electrospray Mass Spectrometry of Oligonucleotides and their Complexes. Rapid Commun. Mass Spectrom. 1996, 10, 47-50.

42. Schnier, P. D.; Klassen, J. S.; Strittmatter, E. F.; Williams, E. R. Activation Energies for Dissociation of Double Strand Oligonucleotide Anions: 
Evidence for Watson-Crick Base Pairing in Vacuo. J. Am. Chem. Soc. 1998, 120, 9605-9613.

43. Bartlett, M. G.; McCloskey, J. A.; Manalili, S.; Griffey, R. H. The Effect of Backbone Charge on the Collision-Induced Dissociation of Oligonucleotides. J. Mass Spectrom. 1996, 31, 1277-1283.

44. Gale, D. C.; Smith, R. D. Characterization of Noncovalent Complexes Formed Between Minor Groove Binding Molecules and Duplex DNA by Electrospray Ionization-Mass Spectrometry. J. Am. Soc. Mass Spectrom. 1995, 6, 1154-1164.

45. Pan, S.; Lee, J. K. Investigation of the Dissociation of Double Stranded Oligodeoxynucleotides in an Ion Trap: Sequence, Length, and Charge Level. Proceedings of the 37th Middle Atlantic Regional Meeting of the American Chemistry Society; New Brunswick, NJ, 2005.

46. Loveless, A. Possible Relevance of $\mathrm{O}^{6}$-Alkylation of Deoxyguanosine to the Mutagenicity and Carcinogenicity of Nitrosamines and Nitrosamides. Nature 1969, 223, 206-207.
47. Lucchesi, P.; Carraway, M.; Marinus, M. G. Analysis of Forward Mutations Induced by N-Methyl-N'-Nitro-N-Nitrosoguanidine in the Bacteriophage P22 mnt Repressor Gene. J. Bacteriol. 1986, 166, 34-37.

48. Richardson, K. K.; Richardson, F. C.; Crosby, R. M.; Swenberg, J. A.; Skopek, T. R. DNA. Base Changes and Alkylation Following In Vivo Exposure of Escherichia coli to N-Methyl-N-Nitrosourea or N-Ethyl-NNitrosourea. Proc. Natl. Acad. Sci. U.S.A. 1987, 84, 344-348.

49. Kuzmich, S.; Marky, L. A.; Jones, R. A. Specifically Alkylated DNA Fragments. Synthesis and Physical Characterization of $\mathrm{d}\left[\mathrm{CGC}\left(\mathrm{O}^{6} \mathrm{Me}\right) \mathrm{GCG}\right]$ and d[CGT(O $\left.\mathrm{O}^{6} \mathrm{Me}\right) \mathrm{GCG}$. Nucleic Acids Res. 1983, 11, 3393-3403.

50. Pauly, G. T.; Powers, M.; Pei, G. K.; Moschel, R. C. Synthesis and Properties of H-ras DNA Sequences Containing $\mathrm{O}^{6}$-Substituted 2'Deoxyguanosine Residues at the First, Second, or Both Positions of Codon 12. Chem. Res. Toxicol. 1988, 1, 391-397. 